\title{
Group Treatment for Depression in Mothers of Young Children Compared to Standard Individual Therapy
}

\author{
Ulrike Frisch $^{\mathrm{a}}$ Maria Hofecker-Fallahpour ${ }^{\mathrm{b}}$ Rolf-Dieter Stieglitz ${ }^{\mathrm{a}}$ \\ Anita Riecher-Rössler ${ }^{\mathrm{a}}$ \\ a Psychiatric Outpatient Department, University of Basel Psychiatric Clinics, and b Private Practice, Basel, Switzerland
}

\section{Key Words}

Depression • Postpartum depression · Group

psychotherapy $\cdot$ Psychotherapy manual $\cdot$ Mothers

\begin{abstract}
Background: Studies on specific psychotherapy for depressed mothers of small children are rare. The aim of the present study was to investigate the effectiveness of a newly developed cognitive-behavioral group intervention for depressed mothers compared to standard individual therapy. Sampling and Methods: In a naturalistic design, 31 mothers suffering from depressive disorders with children aged $\leq 4$ years who had consecutively been admitted to our specialized clinic for mentally ill mothers were assigned to the group treatment, and the following 21 were admitted to the control group receiving standard individual therapy. The group treatment consisted of 12 group sessions and 1 couple session and was administered to five consecutive groups. Participants completed interviews and questionnaires - the Beck Depression Inventory and the Symptom Checklist90- $\mathrm{R}$ - before and 3 months after therapy. Results: The treatment group and the control group showed a significant improvement in their depression, with no significant differences between the two treatment strategies. The women in
\end{abstract}

\section{KARGER}

Fax +4161306 1234

E-Mail karger@karger.ch

www.karger.com
(C) 2012 S. Karger AG, Basel

0254-4962/13/0462-0094\$38.00/0

Accessible online at:

www.karger.com/psp group therapy, however, required fewer antidepressants, and group treatment was observed to be more effective in reducing anger and hostility. Conclusion: This form of group treatment for depressed women in early motherhood may have some important advantages over individual therapy; effects were small, however, and should be replicated in a further study.

Copyright $\odot 2012$ S. Karger AG, Basel

\section{Introduction}

Depression in early motherhood can have a very negative impact on the mothers themselves, on their relationship with their spouse [1], on other family members and on the mother-child relationship [2]. We have learned, primarily from literature on postpartum depression [14], that depression in early motherhood is fairly common. Postpartum depression, i.e. a depressive disorder in the first year after childbirth, shows a prevalence of about $13 \%[3,5]$. Between 30 and $70 \%$ of women who develop postpartum depression continue to have symptoms long after the postpartum period [6], and many mothers start to develop mental health problems in the following years of early motherhood. 
Several therapy options have been found to be effective in treating depression, including antidepressant medication, cognitive behavioral therapy (CBT) and interpersonal psychotherapy (IPT). Because all antidepressants are secreted in breast milk and researchers have raised concerns about the effects of antidepressants on infant development [7-11], it is important to evaluate nonpharmacological interventions for breastfeeding mothers suffering from depression.

The literature on psychotherapy relevant to the specific needs of mothers of small children remains sparse [12-15], and only a few randomized controlled trials have examined the effectiveness of nonbiological treatment approaches [for review, see 16]. Recent studies of group treatment programs (CBT and IPT), mainly focusing on postnatal disorders, were performed without a control group (CG) $[17,18]$ and without a manual. Mulcahy et al. [19] recently published the results of a randomized controlled trial on the effectiveness of group IPT for postnatal depression compared to standard treatment. In the 8 -week trial, both treatment groups significantly improved in terms of mean depression scores. Mothers in the IPT group showed a significant benefit in terms of marital functioning and perceptions of the mother-infant relationship. Griffiths and Barker-Collo [17] reported significant improvements in depression, anxiety and mothering after an 8-session psychoeducational and CBT skills group for postnatal adjustment. However, their study did not include a CG.

We, therefore, developed and manualized a cognitivebehavioral group intervention for depressed mothers of young children $[4,20]$. We included depressed women in the postpartum period as well as women with depression persisting beyond the postpartum phase or developing during early motherhood. The youngest child of each mother had to be less than 4 years of age. The aim of the study was to evaluate the efficacy and effectiveness of this intervention compared to standard individual therapy.

We hypothesized that specific group therapy for mothers with depressive disorders is more effective in reducing depressive symptoms relevant to having young children compared to standard individual therapy.

\section{Methods}

\section{Design of Study}

In this clinical trial, our newly developed group therapy $[4,20]$ was compared to standard individual therapy administered to a CG. The group program consisted of 12 group sessions and 1 couple session administered during a period of 3 months. The pro- gram was administered to five consecutive groups (therapy group, TG) with a total of 31 participants at the Psychiatric Outpatient Department of the University Hospital Basel, Switzerland. Antidepressants were allowed and controlled for.

A CG of 21 participants receiving standard individual therapy for 3 months was compared to the TG in a naturalistic design (see above). Conventional care included support, assistance and treatment, provided in most cases by a psychiatrist in private practice within the community. Symptomatology and other variables (see below) were assessed before therapy and 3 months after the end of therapy.

\section{Participants}

Women were referred to our specialized clinic for mentally ill mothers by the Psychiatric Outpatient Department at the University Hospital Basel, general practitioners, counseling agencies and gynecological clinics. Some mothers came on their own initiative in response to different informational campaigns that we actively distributed in the media during the study.

Inclusion criteria. All mothers fulfilled the International Classification of Diseases, 10th Edition (ICD-10) criteria for first or recurrent episodes of depression or dysthymia (ICD-10 F32, F33, F34.1, F43.2). Mothers with comorbid anxiety disorders, obsessive-compulsive disorders or eating disorders were accepted provided that the depressive disorder was the main diagnosis. Each woman's most recent child had to be below preschool age $(\leq 4$ years). Furthermore, fluent knowledge of the German language and the willingness and ability to participate in group therapy were required. The use of antidepressants was allowed and monitored throughout the study; dosage changes or new prescriptions were avoided during the study period if possible.

Exclusion criteria. Mothers with severe major depression with psychotic symptoms, acute suicidality, addiction disorders and severe personality disorders were excluded from the study.

All human studies were performed in accordance with ethical standards and all persons gave informed consent prior to their inclusion in the study.

\section{Group Therapy}

We began offering group therapy in 1998. A manual was written during the first group treatment and completed through the treatment of subsequent groups before the study started.

This detailed manual allowed suitable preparation for every individual session. Every group therapy session was conducted by one fully trained psychiatrist/psychotherapist and one psychiatrist/psychotherapist in training. The principal therapist in all group sessions was trained in family group therapy, had a degree in CBT and developed and edited the manual. Fidelity to the intervention method was thus guaranteed because the therapist who had developed the manual was the principal therapist in all groups. These TG were run at the Psychiatric Outpatient Department.

To make the therapy sessions more convenient for the mothers, they were allowed to bring their children, who were cared for by a kindergarten nurse in a room nearby. After every session, the group members received a handout summarizing the topics and tasks to be performed at home.

Group psychotherapy was conducted in closed groups of 6-8 participants who attended 12 weekly sessions of $1.5 \mathrm{~h}$ duration.

The group treatment was mainly based on cognitive-behavioral concepts and techniques, such as the tracing of negative auto- 
Table 1. Topics of sessions

\begin{tabular}{|c|c|}
\hline \multicolumn{2}{|c|}{ Session Topics } \\
\hline 1 & Introduction: depression and 3-column technique \\
\hline 2 & $\begin{array}{l}\text { Automatic thoughts, dysfunctional core beliefs, logical } \\
\text { errors }\end{array}$ \\
\hline 3 & $\begin{array}{l}\text { Vicious circles, stressors in daily routine with children, } \\
\text { positive activities }\end{array}$ \\
\hline 4 & $\begin{array}{l}\text { Modifying dysfunctional beliefs, models of stress-coping, } \\
\text { help-seeking strategies }\end{array}$ \\
\hline 5 & Other treatment options for depression besides CBT \\
\hline 6 & Repetition of cognitive and behavioral strategies \\
\hline 7 & Mother-child interaction \\
\hline 8 & Role of parents and parenting \\
\hline 9 & Couple relationship and sexuality \\
\hline 10 & Relapse into depression, suicidality and crisis intervention \\
\hline 11 & Conclusions \\
\hline 12 & Planning of the near future, farewell \\
\hline
\end{tabular}

matic thoughts and errors in logical thinking as well as the detection of dysfunctional core beliefs [for details, see 4, 20]. The mothers were encouraged to undertake positive activities and improve their help-seeking behavior. Psychoeducational elements about depression, the mother-child interaction and the couple relationship in the transition to parenthood were also included in the training program to provide sufficient background information to facilitate the change of attitudes and behaviors. Because the association of maternal depression with the quality of the relationship with the partner is well documented $[1,21]$, we focused especially on this topic. Two of the sessions were dedicated to rehearsing cognitive and behavioral skills, and one session was targeted at the early recognition of relapse and strategies and planning for crisis intervention. Group work was enhanced by home tasks to allow the patients to test the different strategies in the reality of their daily routine, including asking the partner for help and support. After the first sessions of group therapy, the partners were invited to a couple session to discuss the difficulties at home and to improve their understanding of depression. Table 1 describes the topics of the sessions.

\section{Assessments}

To diagnose the mothers, experienced psychiatrists applied the Diagnostic Criteria for Research of the ICD-10 [22] and the International Diagnostic Checklist for ICD-10 [23].

The assessment data of the mothers were based on two questionnaires - the Beck Depression Inventory (BDI) [24] and the Symptom Checklist-90-R (SCL-90-R) [25] - and were collected before and after treatment.

\section{Statistical Analyses}

All analyses were performed using the Statistical Package for Social Sciences (SPSS) for Windows, version 12 (SPSS Inc., 1996).

The differences between the groups were examined using three-way analysis of variance (ANOVA), $t$ test or $\chi^{2}$ test.

A paired t test was used to analyze the changes in the mean scores on the assessment instruments between t0 (baseline) and
Table 2. Sociodemographic variables

\begin{tabular}{|c|c|c|c|}
\hline & $\begin{array}{l}\text { Treatment } \\
\text { group } \\
(\mathrm{n}=31)\end{array}$ & $\begin{array}{l}\text { Control } \\
\text { group } \\
(n=21)\end{array}$ & Statistics \\
\hline Age of mother, years & $\begin{array}{l}33.5 \pm 4.1 \\
(24-40)\end{array}$ & $\begin{array}{l}32.3 \pm 5.1 \\
(21-47)\end{array}$ & $\begin{array}{l}t=-0.93 \\
\text { d.f. }=50 \\
p=0.35\end{array}$ \\
\hline Number of children & $\begin{array}{l}1.6 \pm 0.6 \\
(1-3)\end{array}$ & $\begin{array}{l}1.3 \pm 0.5 \\
(1-2)\end{array}$ & $\begin{array}{l}\mathrm{t}=-1.88 \\
\text { d.f. }=50 \\
\mathrm{p}=0.06\end{array}$ \\
\hline Age of all children, years & $\begin{array}{l}2.4 \pm 2.1 \\
(0-9)\end{array}$ & $\begin{array}{l}1.9 \pm 2.2 \\
(0-9)\end{array}$ & $\begin{array}{l}\mathrm{t}=-0.82 \\
\text { d.f. }=50 \\
\mathrm{p}=0.41\end{array}$ \\
\hline Primiparity, $\mathrm{n}$ & $16(52)$ & $15(71)$ & $\begin{array}{l}\chi^{2}=1.30 \\
\text { d.f. }=1 \\
p=0.26\end{array}$ \\
\hline Partnership, $\mathrm{n}$ & & & $\chi^{2}=0.11$ \\
\hline $\begin{array}{l}\text { Living with partner } \\
\text { Single }\end{array}$ & $\begin{array}{r}26(83.9) \\
5(16.1)\end{array}$ & $\begin{array}{r}16(76.2) \\
5(23.8)\end{array}$ & $\begin{array}{l}\text { d.f. }=1 \\
p=0.74\end{array}$ \\
\hline \multicolumn{4}{|l|}{ Education, $\mathrm{n}$} \\
\hline Training & $2(6.4)$ & 0 & $\chi^{2}=4.74$ \\
\hline Completed apprenticeship & $28(90.3)$ & $17(81)$ & d.f. $=2$ \\
\hline University & $1(3.2)$ & $4(19.0)$ & $\mathrm{p}=0.09$ \\
\hline Professional activity, $\mathrm{n}$ & & & $\chi^{2}=2.75$ \\
\hline Unemployed & $23(74.2)$ & $10(47.6)$ & d.f. $=1$ \\
\hline Employed & $8(25.8)$ & $11(52.3)$ & $\mathrm{p}=0.09$ \\
\hline
\end{tabular}

Results are expressed as means $\pm \mathrm{SD}$ with ranges in parentheses or numbers with percentages in parentheses. $p>0.10$ is nonsignificant.

t1 (after treatment). For categorical variables, a $\chi^{2}$ test was employed.

To compare participants who used antidepressant medication to those who did not, a one-way ANOVA was performed.

Effect sizes (magnitude of therapeutic effect) were calculated as suggested by Rosenthal [26]. Effect sizes below 0.40 indicate poor efficacy, between 0.40 and 0.79 medium efficacy and above 0.80 substantial efficacy of psychotherapy.

\section{Results}

\section{Baseline Data}

No significant differences between the TG and CG were detected in the sociodemographic data (table 2) or the primary diagnosis (table 3 ) at the start of therapy. There was no significant difference in the duration of illness or whether the mothers were experiencing first or recurrent depressive episodes.

There were no significant differences in the BDI and SCL-90-R depression subscale scores between the TG and the CG $(\mathrm{p}=0.78 ; \mathrm{p}=0.62)$. 
Table 3. Primary ICD-10 clinical diagnoses before treatment

\begin{tabular}{|c|c|c|c|}
\hline ICD code & Main diagnosis & $\mathrm{TG}(\mathrm{n}=31)$ & $\mathrm{CG}(\mathrm{n}=21)$ \\
\hline F31.3 & Bipolar affective disorder, current episode moderate depression & 1 & 0 \\
\hline F32.0 & Mild depressive episode & 2 & 0 \\
\hline F32.1 & Moderate depressive episode & 4 & 2 \\
\hline F32.2 & Severe depressive episode without psychotic symptoms & 3 & 4 \\
\hline F33.0 & Recurrent depressive disorder, current episode mild & 1 & 1 \\
\hline F33.1 & Recurrent depressive disorder, current episode moderate & 9 & 4 \\
\hline F33.4 & Recurrent depressive disorder, currently in remission & 3 & 0 \\
\hline F34.1 & Dysthymia & 0 & 2 \\
\hline F41.0 & Panic disorder & 1 & 0 \\
\hline F41.1 & Generalized anxiety disorder & 0 & 2 \\
\hline F43.20 & Adjustment disorder, brief depressive reaction & 3 & 1 \\
\hline F43.21 & Adjustment disorder, prolonged depressive reaction & 3 & 0 \\
\hline
\end{tabular}

Likewise, the other SCL-90-R subscales showed no baseline differences between the groups. The only exception was a tendency toward higher 'anger-hostility' baseline values in the TG $(\mathrm{p}<0.09)$.

\section{Medication}

The percentage of women on antidepressant medication at the beginning of the study was higher in the CG than in the TG. Fourteen (45\%) women in the TG and 15 (71\%) in the CG were being treated with antidepressant medication at the beginning of the study $\left(\chi^{2}\right.$ test $=3.50$, d.f. $=1, p=0.061)$. Medication was prescribed in both groups according to clinical needs and with similar types and dosages of medications, mainly selective serotonin reuptake inhibitors at a therapeutic dose.

Eight women in the TG had been taking antidepressants for more than 3 months, 1 woman for less than 2 months and 5 for less than 1 month. Only 2 women in the CG had been taking antidepressants for more than 3 months, 6 women between 2 and 4 weeks and 7 for less than 2 weeks.

During the 3 months of therapy, there was no need to change the dosage or type of medication in the TG, whereas the dosage had to be increased for 3 women in the CG.

\section{Acceptance of Therapy}

Acceptance of group therapy was assessed using a selfdeveloped questionnaire. On a seven-point Likert scale ranging from -3 (not at all true) to +3 (very true), the patients gave the following mean grades: good relationship with group therapist, 2.77 (SD 0.44); good quality of explanations from the therapists, 2.54 (SD 0.52); good relation- ship with other group participants, 2.08 (SD 1.26); satisfaction with treatment, 2.38 (SD 1.12), and better coping with everyday life, 2.23 (SD 0.83) [for details, see 20]. The mothers accepted group therapy very well. This result was also underlined by the fact that the mean number of sessions attended for mothers participating in the TG was 10 (range 6-12), which is quite high for mothers of small children.

In the CG, the mean number of individual sessions attended was 7 (range 2-13). Seventeen of the 21 mothers were given psychiatric-psychotherapeutic treatment by psychiatrists in private practice, and 3 received psychological counseling. One woman and her husband took part in relationship counseling.

\section{Effects of Psychotherapy}

\section{Beck Depression Inventory}

In both the TG and the CG, there was a highly significant decrease ( $t$ test, $p<0.001$ ) in the BDI values between the pre- and poststudy administrations (see table 4).

There was no effect of medication or group on the BDI, but there was a significant effect of time, meaning the chronological time from the beginning to the end of the intervention. There were no significant interaction effects of group $\times$ medication, group $\times$ time or medication $\times$ time (see table 4 ).

The highly significant pre- to posttreatment decrease in the BDI in both groups is reflected in a correspondingly large effect size: 1.02 for the TG and 1.23 for the CG.

\section{Influence of Medication on the BDI Score}

The decrease in the BDI scores was independent of medication status in both the TG and the CG. 
Table 4. Influence of therapy setting, medication and time on depression score

\begin{tabular}{|c|c|c|c|c|}
\hline & & $\begin{array}{l}\text { BDI before } \\
\text { treatment } \\
(\text { mean } \pm \mathrm{SD})\end{array}$ & $\begin{array}{l}\text { BDI after } \\
\text { treatment } \\
(\text { mean } \pm S D)\end{array}$ & $\begin{array}{l}\mathrm{t} \text { test } \\
\mathrm{p}\end{array}$ \\
\hline $\mathrm{TG}(\mathrm{n}=30)$ & & $21.83 \pm 8.76$ & $12.87 \pm 8.32$ & $\leq 0.001$ \\
\hline $\mathrm{CG}(\mathrm{n}=21)$ & & $22.52 \pm 8.76$ & $11.76 \pm 11.62$ & $\leq 0.001$ \\
\hline $\mathrm{TG}(\mathrm{n}=14)$ & $+\mathrm{AD}$ & $24.71 \pm 8.60$ & $14.50 \pm 10.28$ & 0.003 \\
\hline $\mathrm{TG}(\mathrm{n}=16)$ & $-\mathrm{AD}$ & $19.31 \pm 8.36$ & $11.44 \pm 6.12$ & 0.002 \\
\hline $\mathrm{CG}(\mathrm{n}=15)$ & $+\mathrm{AD}$ & $23.00 \pm 9.84$ & $11.47 \pm 12.98$ & 0.001 \\
\hline \multirow[t]{2}{*}{ CG $(n=6)$} & $-\mathrm{AD}$ & $21.33 \pm 5.78$ & $12.50 \pm 8.22$ & 0.008 \\
\hline & & $\mathrm{F}$ & d.f. & $\mathrm{p}$ \\
\hline
\end{tabular}

Interaction effect

$\begin{array}{llll}\mathrm{G} \times \mathrm{M} & 0.64 & 1.47 & \mathrm{NS} \\ \mathrm{G} \times \mathrm{T} & 0.16 & 1.47 & \mathrm{NS} \\ \mathrm{M} \times \mathrm{T} & 0.78 & 1.47 & \mathrm{NS} \\ \mathrm{G} \times \mathrm{M} \times \mathrm{T} & 0 & 1.47 & \mathrm{NS}\end{array}$

$\mathrm{AD}=$ Antidepressants. Interaction effect by ANOVA: $\mathrm{G}=$ group, $\mathrm{M}=$ medication, $\mathrm{T}=$ time. $\mathrm{NS}=$ Not significant.

Table 5. Levels of significance for the pre- and posttreatment differences in the SCL-90-R for the TG and the CG

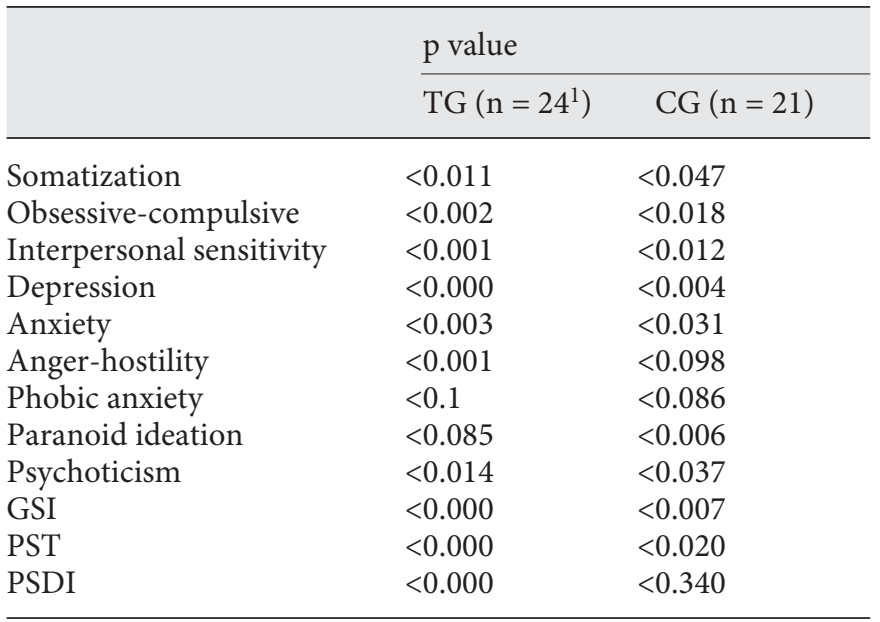

GSI = Global Severity Index; PST = Positive Symptom Total; PSDI $=$ Positive Symptom Distress Index.

${ }^{1}$ Only 24 of the 31 women completed the questionnaire.

Among the TG patients taking antidepressants, the average BDI score decreased from 24.71 to 14.50 ( $\mathrm{p}<$ 0.003 ); among patients who were not taking antidepressants, the average BDI score decreased from 19.31 to 11.44 $(\mathrm{p}<0.002)$.
Even in the CG, both medicated and nonmedicated patients showed a significant improvement in the BDI scores in the pre- to posttreatment comparison (medicated, $\mathrm{p}<0.001$; nonmedicated, $\mathrm{p}<0.008$ ).

\section{The Symptom Checklist-90-R}

It is of interest that in both groups the average poststudy levels for all SCL-90-R scores decreased compared to the prestudy levels.

In both study groups, a highly significant decrease in the level of depression (effect size: TG 0.99; CG 0.95) and significant decreases in the averages of the following scales were evident: somatization; obsessive-compulsive; interpersonal sensitivity; anxiety, and psychoticism. In contrast to the significant decline observed in the TG, the CG only showed a slight tendency toward symptom reduction in the anger-hostility area (effect size: TG 0.73 ; CG 0.52). In the TG, the anger-hostility average decreased from 1.43 before treatment to 0.85 after treatment $(\mathrm{p}<0.001)$, whereas in the CG, the average changed from 0.98 to 0.52 ( $p<0.098)$. In the CG, there was a significant decrease in the area of paranoid ideation, whereas the change in the TG was not significant. Table 5 presents the results of the significance tests.

\section{Discussion}

In line with our first hypothesis, group therapy for mothers of small children is at least as effective as, and in some areas even superior to, standard individual therapy. In both study groups, there was a clear decrease in depressive symptoms following treatment.

A medication effect was excluded by univariate ANOVA, but this result could also be due to the low statistical power. In any case, more patients in the CG took antidepressants than in the TG. Thus, if there was any effect, it would have worked more in the CG and, therefore, speak in favor of the effectiveness of the group therapy. The women in the TG took fewer antidepressants than those in the CG, and those in the TG who took antidepressants had taken them longer than the women in the CG, i.e. no further improvement due to medication was to be expected in the TG. Furthermore, in 3 CG participants, the dose of antidepressants had to be increased after starting on a low dosage at the beginning of the study. This means that the improvement is more likely to be due to medication effects in the CG than in the TG.

The results from the BDI and SCL-90-R indicate that the subjectively experienced mental burden was similar 
at the beginning of the therapy in both study groups. In other words, the mothers in the CG were not more seriously ill, which would have been a rationale for their more frequent use of antidepressants. Furthermore, the patients receiving individual therapy were more frequently prescribed additional medication. The readiness to prescribe drugs as standard therapy for depression was obviously higher among medical staff treating in a standard individual therapy setting. In the TG, the prospect of participating in group psychotherapy and the corresponding positive expectations, both among those referring the mothers to this therapy modality and among the mothers themselves, perhaps led to a more restricted use of medication. The fact that no additional antidepressants had to be administered during the group therapy appears to confirm these positive expectations.

The lower antidepressant use among the TG participants is of high clinical importance if one considers the potential negative effects of medication on breastfed babies, and some of the mothers were breastfeeding during the trial. Indeed, all antidepressants pass into breast milk, and on principle, all adverse drug reactions of the mother to a particular preparation can also be seen in the breastfed baby [27]. The long-term effects of this have not been studied sufficiently $[10,11]$. All in all, the safety of the pharmacological treatment of depression in breastfeeding women remains very controversial [28]. In particular, there are concerns about the effects of medication on the development of the organ systems in infants, e.g. the CNS $[7,29]$, which is one of the reasons why breastfeeding mothers often refuse antidepressant treatment.

Interestingly, there was a tendency towards a stronger decrease in aggressiveness and hostility in the TG, a result that is also of great relevance in the treatment of mentally ill mothers of small children. There was a stronger symptom reduction on the SCL-90-R dimension of aggression/hostility in the TG. This subscale relates to thoughts, feelings or actions that are characteristic of the negative emotional conditions of anger and also detects aggression, irritability, resentment and depressive mood. These emotions were the focus of the group therapy, and the mothers in this group learned how to deal with their aggressive and hostile feelings. Thus, the participating mothers definitely benefited from feeling less hostile and tense in the care of their babies and in interactions with their partners. Reduced hostility towards the child and one's partner may improve mother-child interactions and thereby the future development of the child $[2-4,20]$. However, it is possible that the stronger decline in the TG may be explained partly by the fact that the baseline val- ues in this group were higher than in the CG, meaning that more of a change was possible.

In contrast to the experience of other authors, who found mothers to be reluctant to enter group therapy [30], we found a high level of acceptance of group therapy. This was reflected by the very strong interest in participating in group rather than individual therapy, by the high average attendance rate of those in the TG and by the positive feedback from the mothers about group therapy. One should be aware, however, that the offer of a nursery during the TG made it easier for the women to attend therapy.

The following limitations of the study should, however, be noted:

- We had to choose a waiting list CG design and were not able to allocate the women randomly to the TG or the CG for various reasons. The number of acutely ill mothers in our catchment area was small (hence the small sample size) and insufficient to assign mothers randomly to the two groups. In addition, the affected mothers were enthusiastic about group therapy as soon as it was offered, and access to the group could hardly be denied. In these cases, a waiting list control is considered acceptable. Because we gathered the samples in two different time frames, there may have been contamination of historical, event-related or seasonal factors. However, seasonal influences were excluded by starting both groups in the same season.

- We did no follow-up analysis to evaluate the long-term therapeutic effect.

- We did not assess the influence of outside forms of social support. However, this was true for both groups, and there is no reason why this influence should differ between the groups. It would be desirable to encourage the partners of the women to attend the sessions more often to provide support and to improve their understanding of depression, irritability and anxiety.

- One could also critically note that only self-assessment instruments were used.

- Finally, a more precise characterization of psychotherapeutic interventions in the CG was not undertaken. In our investigation, structured group therapy was compared to standard individual therapy for mothers with depressive disorders within the catchment area. In the vast majority of cases, the CG mothers were treated by a trained psychiatrist with experience in treating postpartum diseases and whose therapeutic interventions were highly specific to the special needs of mothers of small children. It is possible that a larger difference between the two treatment modalities 
would be seen in other catchment areas where this special knowledge is not so widely available.

Although the study was not designed in a way to allow the general conclusion that group therapy is more effective than individual therapy, as the conditions of both groups differ in more aspects than the setting, there are many arguments in favor of group therapy. By participating in group therapy, mothers can perceive that others are also affected, allowing them to realize that they are not alone. In the exchange of experiences, their feelings of stigmatization and isolation that are often associated with depression can be reduced. Incidents that took place during the postpartum period can be shared and vicariously experienced by others, thereby contributing to interpersonal learning. In the group therapy setting, areas of social competence can be trained more effectively. This may be one of the reasons why afflicted mothers found this option so attractive. Furthermore, childcare, which often prevents mothers from seeking help, can be offered much more easily for the whole group than for many individual therapies, and last but not least, the child carer can give feedback regarding the children's behavior and well-being.

Economic aspects also support group therapy. The costs of group therapy are comparatively lower than those of individual treatment, and group therapy makes better use of the often limited availability of therapists who are experienced in this subspecialty. Another cost aspect that should be considered is the tendency toward less frequent use of antidepressants observed among group therapy participants.

In summary, a comparably good success rate for treating maternal depression was noted in both the TG and CG settings. In group therapy, however, fewer concomitant medications were required, which is of the utmost relevance, especially for breastfeeding mothers. Likewise, a stronger decrease in anger/hostility scores was achieved in the TG, which could be of great importance for the mother-child relationship and for preventing childhood traumatization.

\section{Acknowledgment}

We thank the women who participated in the study.

\section{Disclosure Statement}

The authors declare that they have no conflicts of interest.

\section{References}

1 Akincigil A, Munch S, Niemczyk KC: Predictors of maternal depression in the first year postpartum: marital status and mediating role of relationship quality. Soc Work Health Care 2010;49:227-244.

2 Murray L, Cooper PJ: Postpartum depression and child development. Psychol Med 1997;27:253-260

$\checkmark 3$ Riecher-Rössler A: Psychiatric disorders and illnesses after childbirth (in German). Fortschr Neurol Psychiatr 1997;65:97-107.

4 Hofecker-Fallahpour M, Zinkernagel C, Frisch U, Neuhofer C, Stieglitz RD, RiecherRössler A: Was Mütter depressiv macht... und wodurch sie wieder Zuversicht gewinnen. Ein Therapiehandbuch. Bern, Huber, 2005.

5 O'Hara MW, Swain AM: Rates and risk of postpartum depression: a meta-analysis. Int Rev Psychiatry 1996;8:37-54.

6 Cooper PJ, Murray L: Course and recurrence of postnatal depression. Evidence for the specificity of the diagnostic concept. Br J Psychiatry 1995;166:191-195.
7 Nulman I, Rovet J, Stewart DE, Wolpin J, Pace-Asciak P, Shuhaiber S, Koren G: Child development following exposure to tricyclic antidepressants or fluoxetine throughout fetal life: a prospective, controlled study. Am J Psychiatry 2002;159:1889-1895.

8 Freeman MP: Postpartum depression treatment and breastfeeding. J Clin Psychiatry 2009;70:e35.

$\checkmark 9$ Kendall-Tackett K, Hale TW: The use of antidepressants in pregnant and breastfeeding women: a review of recent studies. J Hum Lact 2010;26:187-195.

10 Lanza di Scalea T, Wisner KL: Antidepressant medication use during breastfeeding. Clin Obstet Gynecol 2009;52:483-497.

-11 Ng RC, Hirata CK, Yeung W, Haller E, Finley PR: Pharmacologic treatment for postpartum depression: a systematic review. Pharmacotherapy 2010;30:928-941.

12 Meager I, Milgrom J: Group treatment for postpartum depression: a pilot study. Aust NZ J Psychiatry 1996;30:852-860.

13 O’Hara MW, Stuart S, Gorman LL, Wenzel A: Efficacy of interpersonal psychotherapy for postpartum depression. Arch Gen Psychiatry 2000;57:1039-1045.
14 Clark R, Tluczek A, Wenzel A: Psychotherapy for postpartum depression: a preliminary report. Am J Orthopsychiatry 2003;73:441454

15 Stuart S, O'Hara MW: Treatment of postpartum depression with interpersonal psychotherapy. Arch Gen Psychiatry 1995;52:75-76.

16 Dennis CL, Hodnett E: Psychosocial and psychological interventions for treating postpartum depression. Cochrane Database Syst Rev 2007;4:CD006116.

17 Griffiths P, Barker-Collo S: Study of a group treatment program for postnatal adjustment difficulties. Arch Womens Ment Health 2008;11:33-41.

18 Reay R, Fisher Y, Robertson M, Adams E, Owen C, Kumar R: Group interpersonal psychotherapy for postnatal depression: a pilot study. Arch Womens Ment Health 2006;9: 31-39.

19 Mulcahy R, Reay RE, Wilkinson RB, Owen $\mathrm{C}$ : A randomised control trial for the effectiveness of group interpersonal psychotherapy for postnatal depression. Arch Womens Ment Health 2010;13:125-139. 
20 Hofecker-Fallahpour M, Zinkernagel-Burri C, Stockli B, Wusten G, Stieglitz RD, Riecher-Rössler A: Gruppentherapie bei Depression in der frühen Mutterschaft: Erste Ergebnisse einer Pilotstudie. Nervenarzt 2003;74: 767-774.

21 Segre LS, O'Hara MW, Arndt S, Stuart S: The prevalence of postpartum depression: the relative significance of three social status indices. Soc Psychiatry Psychiatr Epidemiol 2007;42:316-321.

22 World Health Organisation: The ICD-10 Classification of Mental and Behavioral Disorders. Diagnostic Criteria for Research. Geneva, World Health Organisation, 1993.
23 Hiller W, Zaudig M, Mombour W (eds): Internationale Diagnosen Checklisten für ICD-10. Bern, Huber, 1995.

24 Hautzinger M, Bailer M, Worall H, Keller F: Beck-Depressions-Inventar (BDI). Testhandbuch. Bern, Huber, 1994.

25 Franke G: The Symptom Check List by Derogatis (German version). Manual. Göttingen, Hogrefe, 1995.

26 Rosenthal R: Metaanalytic procedures for social research. Newbury Park, Sage, 1984.

27 Maschi S, Clavenna A, Campi R, Schiavetti B, Bernat M, Bonati M: Neonatal outcome following pregnancy exposure to antidepressants: a prospective controlled cohort study. BJOG 2008;115:283-289.
28 Riecher-Rössler A, Heck A: Psychopharmakotherapie in Schwangerschaft und Stillzeit; in Riecher-Rössler A (ed): Psychische Erkrankungen in Schwangerschaft und Stillzeit. Basel, Karger, 2012, pp 69-89.

29 Bader A, Frisch U, Wirz-Justice A, RiecherRössler A: Depression during pregnancy and its treatment (in German). Nervenarzt 2010; 81:267-276.

30 Cooper PJ, Murray L, Wilson A, Romaniuk $\mathrm{H}$ : Controlled trial of the short- and longterm effect of psychological treatment of post-partum depression. I. Impact on maternal mood. Br J Psychiatry 2003;182:412-419. 